\title{
Retear of anterior cruciate ligament grafts in female basketball players: a case series
}

\author{
Yoshinari Tanaka ${ }^{1 *}$, Yasukazu Yonetani ${ }^{1}$, Yoshiki Shiozaki ${ }^{3}$, Takuya Kitaguchi ${ }^{2}$, Nozomi Sato ${ }^{2}$, Shinya Takeshita ${ }^{2}$,
} Shuji Horibe ${ }^{1}$

\begin{abstract}
Background: Incidence of anterior cruciate ligament (ACL) injuries in young female basketball players is higher than that in male basketball players. Graft retears are more frequent with the increasing number of $\mathrm{ACL}$ reconstructions. The present study aimed to examine the incidence of retears in competitive female basketball players.
\end{abstract}

Methods: Sixty-four female basketball players (aged 12 to 29 years) who underwent primary anatomic doublebundle $\mathrm{ACL}$ reconstruction using hamstring grafts participated in the study. We investigated incidence, mechanism, and patient characteristics of ACL graft retears. Mann-Whitney $U$ test was used for statistical analysis, and the level of significance was determined at $P<0.05$.

Results: Six patients suffered from $A C L$ graft retear (9.4\%). Mean duration between primary $A C L$ reconstruction and incidence of retears was 11.7 months. However, there were no other postoperative graft ruptures after 24 months. Primary injury and retear mechanisms varied by patient. At six months after the primary ACL reconstruction surgery, mean quadriceps and hamstring strengths were $81 \%$ and $87 \%$, respectively, indicating favorable recovery of muscle strength. However, preoperative quadriceps and hamstring strength in the retear group were $65 \%$ and $71 \%$, respectively. In particular, preoperative quadriceps strength in the retear group demonstrated a lower value than that in the uninjured group $(P<0.05)$.

Conclusions: We observed a high incidence of $A C L$ graft retears in competitive female basketball players, as previously reported. Considering the timing of graft retear occurrences, an early return to playing basketball should be avoided following $\mathrm{ACL}$ reconstruction. Closer attention should be paid to player preoperative condition, as well as muscle strength and postoperative status.

\section{Introduction}

Anterior cruciate ligament $(\mathrm{ACL})$ rupture is a disabling knee injury which frequently occurs in young athletes. Previous studies have critically assessed risk factors for primary ACL injury, including variables such as gender, levels of sports activity, and anatomical characteristics $[1,2]$. Female to male ratio of ACL injuries in basketball players was 3.6 and 4.5 in high school and in college, respectively [3].

ACL reconstruction is currently the gold standard to restore knee function after ACL rupture [4], but longterm efficacy has not been fully established [5]. ACL reconstruction using hamstring tendons has become a

\footnotetext{
* Correspondence: yoshi-t@fa3.so-net.ne.jp

'Department of Orthopaedic Surgery, Osaka Rosai Hospital, Sakai, Japan
}

popular procedure because of its lower risk of donor site morbidity [6-8]. In addition, recent improvement in operative procedures has made it possible to perform anatomical double-bundle ACL reconstruction. This offers several advantages over the traditional Rosenberg's one or two femoral sockets ("bi-socket") procedure, including better biomechanical outcomes and more favorable clinical results [9-11].

However, with the increasing number of ACL reconstructions, graft failures have become more frequent. Rate of graft failures is reported as high as $8 \%$ of primary ACL reconstructions [12], and causes for failures can be classified into three categories: technical errors, biological failures, and traumatic failures. However, risk factors of graft retears remain unknown [13,14], and a single study has examined the risk factors for ACL graft 
retears [15]. The authors described the return to competitive sports as requiring movements such as side-stepping, pivoting, and jumping, and playing basketball was one risk factor for repeated ACL injury. Despite these facts, most athletes hope to return to sports activity following ACL reconstruction. The present study aimed to examine the incidence of ACL graft retear in female basketball players.

\section{Methods}

Patients

Between January 2004 and December 2006, primary anatomic double-bundle ACL reconstruction was performed on 104 knees in 101 female basketball players. Of those, 64 knees in 64 patients were included in the current study according to the following inclusion criteria:

1. Patient had a normal contralateral knee at the primary ACL reconstruction.

2. Patient underwent ACL reconstruction within 18 months after the injury.

3. Preoperative and postoperative muscle strength data were collected with the use of a Cybex II dynamometer (Lumex, Ronkonkoma, NY).

4. Patient received postoperative follow-up for at least eight months, at which point they were permitted to return to their sports activity.

5. Patient regained knee stability at six months after the surgery. Mean age of the patients was 16.2 years (range: 12 to 29 years) at the time of primary ACL reconstruction. Preoperatively, 59 patients $(92.2 \%)$ played basketball at a competitive level (Table 1). Postoperatively, 35 patients $(54.7 \%)$ returned to play at a competitive level and 13 patients (20.3\%) played recreationally, while 11 patients $(17.2 \%)$ did not return to play because of school graduation (Table 1).

\section{Surgical Procedure}

We performed anatomic double-bundle ACL reconstruction using hamstring autografts [16]. Autogenous semitendinosus tendon grafts were used for graft materials. After identification of the femoral and tibial footprints of the ACL, two $2.4 \mathrm{~mm}$ guide pins were inserted from the lateral femoral cortex to points between the resident's ridge and the posterior margin of the articular

\section{Table 1 Preoperative and postoperative activity levels}

\begin{tabular}{ccc}
\hline Activity levels & Preoperative (n) & Postoperative (n) \\
\hline Competitive & 59 & 35 \\
Vigorous recreational & 3 & 7 \\
Light recreational & 2 & 6 \\
ADL & 0 & 11 \\
Unknown & 0 & 5
\end{tabular}

cartilage using the anterolateral entry femoral aimer (Smith \& Nephew Endoscopy, MA). For the tibia, a 2.4 $\mathrm{mm}$ wire was inserted into the center of the posterolateral fiber at an angle of approximately $55^{\circ}$ to the sagittal plane and $10^{\circ}$ to the tibial axis using the guide, and another $2.4 \mathrm{~mm}$ wire was inserted into the center of the anteromedial fiber at an angle of approximately $45^{\circ}$ to the sagittal plane and $20^{\circ}$ to the tibial axis also using the guide. Each wire was overdrilled with a drill bit of appropriate $(5-6 \mathrm{~mm})$ diameter. Posterolateral and anteromedial grafts were fixed with EndoButton (Smith \& Nephew Endoscopy, MA) to the femur. Two doublespike plates (DSP; MEIRA Corp., Nagoya, Japan; US Patent No. 6117,139,21) were used for the tibial fixation [17]. An initial tension of $1 \mathrm{MPa}$ (approximately 20 to $25 \mathrm{~N}$ for each graft) was applied. After retightening the tension suture by repetitive manual pulling to remove stress relaxation, each graft was fixed at $15^{\circ}$ to $20^{\circ}$ of knee flexion with DSP and cancellous screws.

\section{Postoperative Rehabilitation and Return to Basketball}

Patient knees were immobilized with braces postoperatively for two weeks. We allowed partial weight bearing at three weeks, and full weight bearing at four weeks. Jogging and running were allowed at three and four months, respectively. Patients were allowed to return to their previous activity levels after eight to ten months if postoperative quadriceps and hamstring strength levels of their injured leg improved to approximately $85 \%$ and $80 \%$, respectively, at six months. None of the patients complained of subjective instability after their return to play. In addition, we observed no evident objective instability as assessed by the Lachman test, pivot shift test and KT-2000 arthrometer. Side-to-side difference of the anterior laxity at maximum load measured by KT2000 was less than $2 \mathrm{~mm}$ in all cases.

\section{ACL Graft Retear}

Graft retear was defined as follows:

1. Patient experienced an evident traumatic episode on the operated knee.

2. The knee became unstable after the re-injury.

3. Magnetic resonance imaging (MRI) confirmed the graft rupture.

\section{Muscle Strength Testing}

We assessed the strength of the quadriceps and hamstring at $60^{\circ}$ per second using a Cybex II dynamometer, both preoperatively and six months after surgery. Peak torque value was calculated and strength was expressed as a percentage of the uninvolved limb. Body weight ratio (BWR) for each muscle strength as well as the hamstring to quadriceps (HQ) ratio were also recorded. 


\section{Statistical analysis}

Statistical analysis was performed using SPSS for Windows software (SPSS Inc., Chicago, IL). Mann-Whitney $U$ test was used to examine the differences between the uninjured and retear groups. The level of significance was determined at $P<0.05$.

\section{Results}

Incidence of retear of the ACL grafts in competitive female basketball players

Of the 64 patients, ACL graft retears occurred in six patients $(9.4 \%)$. Mean duration between the index operation and the retears was 11.7 months (range: 8.0 to 15.7 months). Follow-up with 28 patients (43.8\%) over a 24-month period revealed that none of these experienced graft ruptures (Figure 1).

\section{Mechanism of graft retears}

The most common maneuvers that caused the primary injuries were landing (36.0\%), stopping (18.8\%), and cutting $(18.8 \%)$, comparable with those described in previous reports [18]. Mechanisms for primary injury and graft retear are described in Table 2 . None of the patients sustained re-injury by the same mechanism that caused the primary injury. Moreover, we observed an increased number of retears caused by the cutting maneuver mechanism.

\section{Characteristics of patients with retears}

Patient demographics in the retear group are summarized in Table 3. Mean preoperative period for retear patients (1.9 months, range: 1.5 to 2.9 months) was shorter than that for uninjured patients (4.4 months,
Table 2 Mechanisms of primary injury and retear

\begin{tabular}{lll}
\hline Patient & Primary injury & Retear \\
\hline 1 & Landing & Cutting \\
2 & Direct blow & Cutting \\
3 & Stop & Direct blow \\
4 & Landing & Direct blow \\
5 & Unknown & Cutting \\
6 & Stop & Landing \\
\hline
\end{tabular}

range: 0.7 to15.1 months), but this difference was not statistically significant $(P=0.11)$.

Cybex II dynamometer measurements are reported in Table 4. Mean quadriceps and hamstring strength at six months after surgery were $81 \%$ and $87 \%$, respectively, indicating favorable recovery of muscle strength. Preoperative quadriceps and hamstring strength of the injured leg in the retear group were lower than those in the uninjured group (Figure 2). In particular, preoperative quadriceps strengths in the uninjured and retear group were $78 \%$ and $65 \%$, respectively, with a statistically significant difference $(P<0.05)$. Preoperative hamstring strength values in the uninjured and retear group were $77 \%$ and $71 \%$, respectively, with no statistically significant difference $(P=0.13)$ (Figure 2).

\section{Discussion}

Our case series revealed an ACL graft retear rate in female basketball players of $9.4 \%$. Some studies which reported results from patellar tendon and hamstring reconstruction also described incidence of hamstring ACL graft retear, but did not necessarily focus on graft ruptures [15,19-22]. According to these reports, the

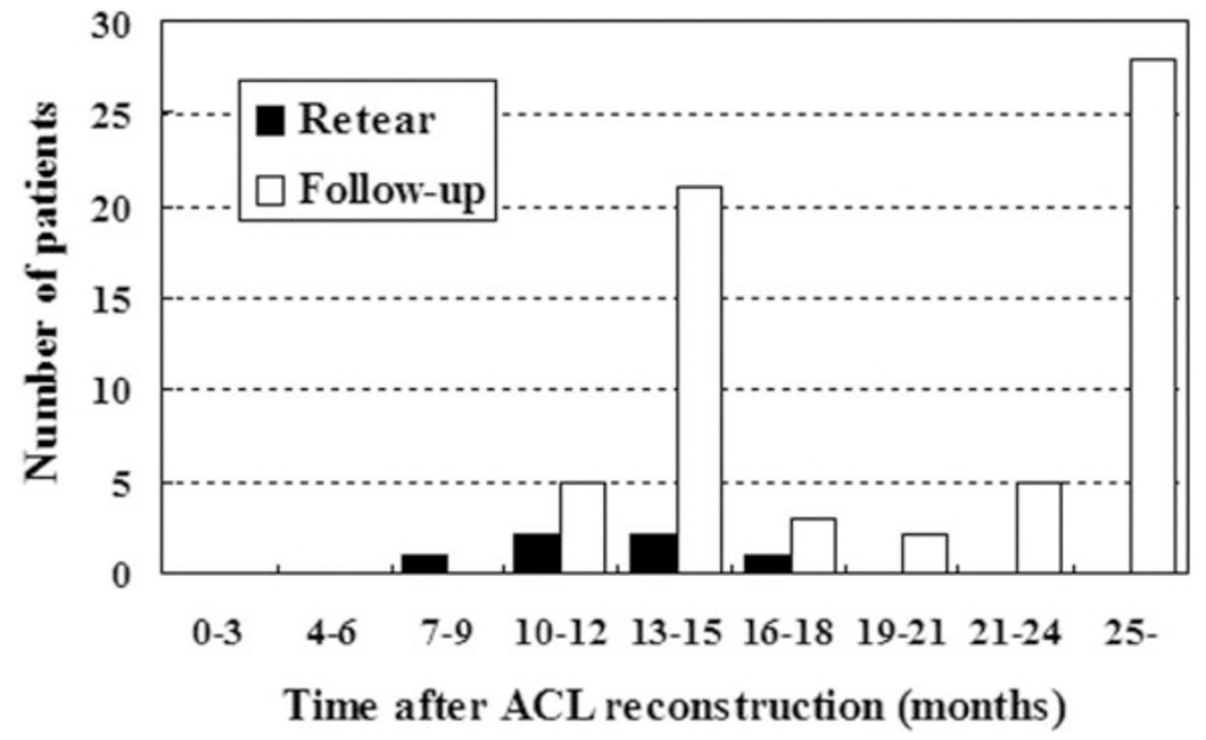

Figure 1 Number of patients with ACL graft retear (black bars) and those who received follow-up (white bars) after reconstruction. 
Table 3 Patient demographics

\begin{tabular}{lll}
\hline & Total patients & Injured patients \\
\hline Total number of patients & 64 & 6 \\
Total reconstructions performed & 64 & 6 \\
$\begin{array}{l}\text { Age at the time of surgery (year) } \\
\text { (range) }\end{array}$ & $16.2(12-29)$ & $15.8(14-18)$ \\
BMI (range) & $21.7(17.6-27.2)$ & $20.8(18.9-23.9)$ \\
$\begin{array}{l}\text { Preoperative period (months) } \\
\text { Time between operation and }\end{array}$ & 4.2 & 1.9 \\
returning to sports & 9.9 & 9.8 \\
$\begin{array}{l}\text { Meniscal lesion } \\
\quad\end{array}$ & \\
$\quad$ Medial meniscus & $23(35.9 \%)$ & $1(16.7 \%)$ \\
$\quad$ Lateral meniscus & $26(45.3 \%)$ & $3(50.0 \%)$ \\
Cartilage lesion & $19(29.7 \%)$ & $1(16.7 \%)$ \\
\hline
\end{tabular}

retear rate ranged from $2 \%$ to $8 \%$. Salmon et al. concluded that risk factors of graft retear included return to competitive sports that require side-stepping, pivoting or jumping [15]. Their findings are consistent with our data with regard to the high incidence of retear in female basketball players.

Previous reports describe external and internal risk factors of primary ACL injury in female athletes [1,2]. External factors include the type of competition, shoesurface interface, and muscle strength. Internal factors include anatomical, hormonal, and neuromuscular risk factors. However, risk factors of ACL graft retears remain unknown.

Salmon et al. reported incidence and risk factors of ACL graft rupture and contralateral ACL rupture over five years after reconstruction [15]. Repeated ACL injury occurred in $12 \%$ of the patients, and risk factors included a return to competitive sports that require side-stepping, pivoting, or jumping, as well as the contact mechanism of the index injury. Rate of graft
Table 4 Preoperative and postoperative Cybex II testing data

\begin{tabular}{lrrr}
\hline & Preop. & Postop. & $\boldsymbol{P}$ \\
\hline $\begin{array}{l}\text { Ham. peak torque (Nm) } \\
\text { (uninvolved) }\end{array}$ & $58.5 \pm 10.6$ & $64.8 \pm 14.0$ & 0.01 \\
Ham. peak torque (Nm) (involved) & $44.7 \pm 11.6$ & $56.6 \pm 16.6$ & $<0.01$ \\
Ham. BWR (\%) (uninvolved) & $105.9 \pm 18.9$ & $117.3 \pm 24.5$ & $<0.01$ \\
Ham. BWR (\%) (involved) & $81.0 \pm 21.3$ & $102.5 \pm 29.2$ & $<0.01$ \\
$\begin{array}{l}\text { Q-ceps. peak torque (Nm) } \\
\text { (uninvolved) }\end{array}$ & $121.2 \pm 23.6$ & $134.7 \pm 27.2$ & $<0.01$ \\
Q-ceps. peak torque (Nm) & $91.3 \pm 21.7$ & $109.7 \pm 29.3$ & $<0.01$ \\
(involved) & & & \\
Q-ceps. BWR (\%) (uninvolved) & $219.2 \pm 40.7$ & $244.1 \pm 48.6$ & $<0.01$ \\
Q-ceps. BWR (\%) (involved) & $165.3 \pm 38.2$ & $198.6 \pm 51.4$ & $<0.01$ \\
Ham. strength (\%) & $76.7 \pm 16.0$ & $87.3 \pm 17.0$ & $<0.01$ \\
Q-ceps. strength (\%) & $76.4 \pm 17.2$ & $81.7 \pm 16.6$ & 0.01 \\
H/Q ratio (\%) (uninvolved) & $49.1 \pm 7.7$ & $48.6 \pm 7.8$ & 0.63 \\
H/Q ratio (\%) (involved) & $50.0 \pm 10.5$ & $53.1 \pm 14.8$ & 0.24 \\
\hline
\end{tabular}

ruptures and contralateral ACL ruptures were both $6 \%$, although graft ruptures occurred significantly earlier than did contralateral ACL ruptures. According to their data, approximately $70 \%$ of all ACL graft ruptures occurred postoperatively, within a 24-month period [15]. Our data show that all graft retears were observed within the first 18 months. Furthermore, mechanisms of graft retear were completely different from those of the primary injury. While routine physical examination before re-injury revealed no instability in patients in the retear group, the remodeling phase of transplanted grafts is likely to continue throughout this period, and failures in graft maturation may influence retears. Based on these results, we would not recommend an early return to playing basketball.

Mean preoperative period of the retear group was shorter than that of the uninjured group, but the

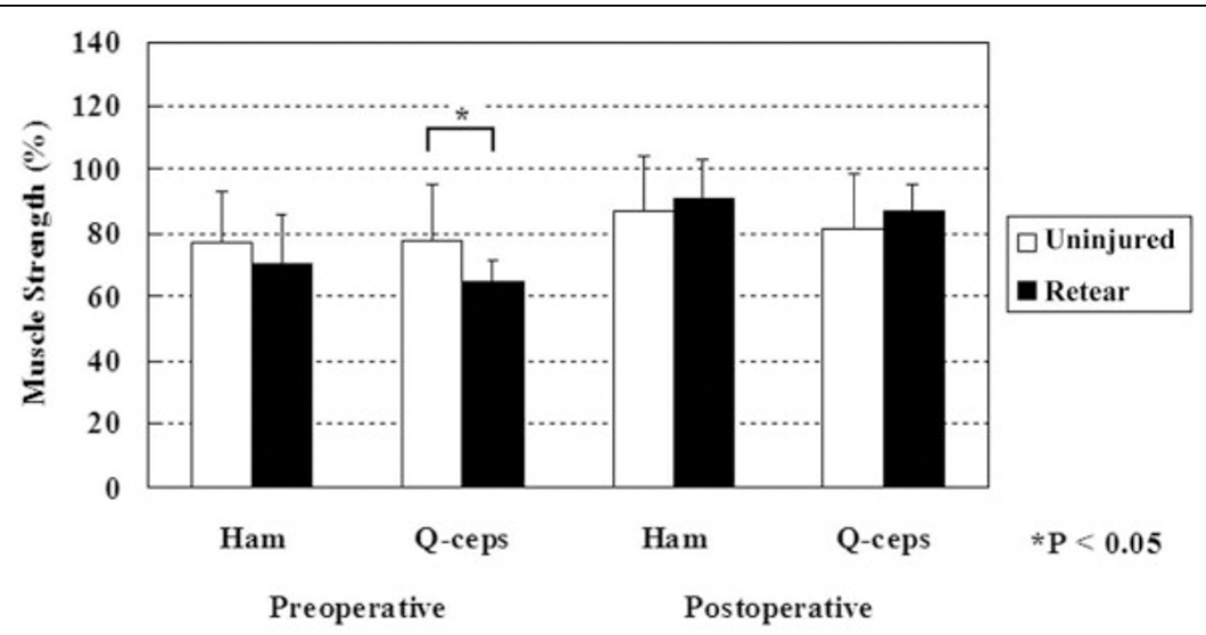

Figure 2 Hamstring (Ham) and quadriceps (Q-ceps) preoperative and postoperative strength. 
difference was not statistically significant. While we lack scientific evidence to support this, it is possible that a short preoperative duration might influence player condition. First, this could lower the likelihood that they will restore their physical condition including muscle strength, balance, and agility before ACL reconstruction. Second, it may influence their sense of fear. A long preoperative period seems to induce a sense of fear towards returning to their previous sports activity. However, in the absence of fear, patients do not hesitate to return to their sport after ACL reconstruction. As such, a shorter preoperative period may lead to ACL graft retear.

Mean age of the players was lower in the retear group than that in the uninjured group, but the difference was not statistically significant. However, all graft retears occurred in high school players. As young players are not supervised by an athletic trainer in most high schools, surgeons and physical therapists should provide stringent follow-up following ACL reconstruction.

Interestingly, preoperative quadriceps strength in the injured graft group was significantly lower than that in the uninjured group. A study by de Jong et al. revealed an association between preoperative quadriceps strength and postoperative functional performance [22]. The authors showed that an increased preoperative quadriceps deficit resulted in a lower postoperative function at six and nine months. In addition, they observed a quadriceps strength deficit of almost $20 \%$, which persisted for one year. Residual quadricep weakness after ACL reconstruction has been shown in several studies [23-27]. Measured with a Cybex dynamometer, Keays et al. reported a $12 \%$ quadriceps strength deficit at $60^{\circ}$ per second and a $10 \%$ deficit at $120^{\circ}$ per second at six months [26]. Kobayashi et al. showed an approximate $10 \%$ quadriceps deficit postoperatively even after two years [25]. Furthermore, many reports on chronic ACLdeficiency cases found an association between postoperative quadriceps deficit and functional performance [23,27-29]. However, our case series found no significant difference in postoperative muscle strength between the uninjured and injured groups. Accurate clinical relevance of preoperative quadriceps deficit in ACL graft retears remains unclear at the present time.

We hypothesize that patients who showed strength deficits might have deficits in agility, balance, and proprioception. Rendstrom et al. noted that prevention of primary ACL injuries required a program which includes muscle strength and power exercises, neuromuscular training, and plyometrics and agility training [2]. When deficits in these elements were retained postoperatively, patients returned to basketball not fully healed and in unsafe conditions. Further studies are required to clarify if preoperative muscle weakness reflects deficits in other elements.
Limitations of this study include the lack of functional assessment, the relatively short duration of follow-up, and the small number of retear cases. We recognize the importance of functional assessment, as well as evaluation of muscle strength in patients prior to returning to sports activity. As data were incomplete in most patients, we excluded results of the functional tests from the present study. Regarding follow-up duration, further observation is required to demonstrate long-term results of ACL reconstruction. However, our data in the present study demonstrated that re-injury occurred within 18 months after the index surgery, representing the reality of ACL graft retears. Further cases are required to clarify the validity of the present study results.

\section{Conclusions}

We examined risk factors of graft retear in female basketball players after anatomic double-bundle ACL reconstruction using hamstring autografts. ACL graft retears occurred in $9.4 \%$ of female basketball players in our study. Considering the timing and mechanism of graft retears, an early return to basketball should be avoided after ACL reconstruction. Preoperative conditions such as muscle strength and preoperative period, as well as postoperative status require close attention.

\section{Author details}

'Department of Orthopaedic Surgery, Osaka Rosai Hospital, Sakai, Japan.

${ }^{2}$ Department of Rehabilitation, Osaka Rosai Hospital, Sakai, Japan.

${ }^{3}$ Department of Orthopaedic Surgery, Seifu Hospital, Sakai, Japan.

\section{Authors' contributions}

YT drafted the manuscript. SH and YY contributed to study design and manuscript structure. TK, NS and ST contributed to muscle strength assessment. YS advised clinical opinions for assessing retear cases. All authors have read and approved the final manuscript.

\section{Competing interests}

The authors declare that they have no competing interests.

Received: 5 November 2009 Accepted: 9 March 2010

Published: 9 March 2010

\section{References}

1. Arendt $E$, Dick R: Knee injury patterns among men and women in collegiate basketball and soccer. NCAA data and review of literature. Am J Sports Med 1995, 23:694-701.

2. Renstrom P, Ljungqvist A, Arendt E, Beynnon B, Fukubayashi T, Garrett W, Georgoulis T, Hewett TE, Johnson R, Krosshaug T, Mandelbaum B, Micheli L, Myklebust G, Roos E, Roos H, Schamasch P, Shultz S, Werner S, Wojtys E, Engebretsen $\mathrm{L}$ : Non-contact $\mathrm{ACL}$ injuries in female athletes: an International Olympic Committee current concepts statement. $\mathrm{Br} J$ Sports Med 2008, 42:394-412.

3. Prodromos CC, Han Y, Rogowski J, Joyce B, Shi K: A meta-analysis of the incidence of anterior cruciate ligament tears as a function of gender, sport, and a knee injury-reduction regimen. Arthroscopy 2007, 23:1320-1325.

4. Dye SF, Wojtys EM, Fu FH, Fithian DC, Gillquist I: Factors contributing to function of the knee joint after injury or reconstruction of the anterior cruciate ligament. J Bone Joint Surg [Am] 1998, 80A:1380-1393.

5. Yamaguchi S, Sasho T, Tsuchiya A, Wada Y, Moriya $\mathrm{H}$ : Long term results of anterior cruciate ligament reconstruction with iliotibial tract: 6-, 13-, and 
24-year longitudinal follow-up. Knee Surg Sports Traumatol Arthrosc 2006, 14:1094-1100.

6. Maeda A, Shino K, Horibe S, Nakata K, Buccafusca G: Anterior cruciate ligament reconstruction with multistranded autogenous semitendinosus tendon. Am J Sports Med 1996, 24:504-509.

7. Giron F, Aglietti P, Cuomo P, Mondanelli N, Ciardullo A: Anterior cruciate ligament reconstruction with double-looped semitendinosus and gracilis tendon graft directly fixed to cortical bone: 5 -year results. Knee Surg Sports Traumatol Arthrosc 2005, 13:81-91

8. Hamada M, Shino K, Horibe S, Mitsuoka T, Miyama T, Shiozaki Y, Mae T: Single- versus bi-socket anterior cruciate ligament reconstruction using autogenous multiple-stranded hamstring tendons with endoButton femoral fixation: A prospective study. Arthroscopy 2001, 17:801-807.

9. Yagi M, Wong EK, Kanamori A, Debski RE, Fu FH, Woo SL: Biomechanical analysis of an anatomic anterior cruciate ligament reconstruction. $\mathrm{Am} J$ Sports Med 2002, 30:660-666.

10. Mae T, Shino K, Matsumoto N, Hamada M, Yoneda M, Nakata K: Anatomical two-bundle versus Rosenberg's isometric bi-socket $\mathrm{ACL}$ reconstruction: a biomechanical comparison in laxity match pretension. Knee Surg Sports Traumatol Arthrosc 2007, 15:328-334

11. Muneta T, Koga H, Mochizuki T, Ju YJ, Hara K, Nimura A, Yagishita K, Sekiya I: A prospective randomized study of 4 -strand semitendinosus tendon anterior cruciate ligament reconstruction comparing singlebundle and double-bundle techniques. Arthroscopy 2007, 23:618-628.

12. Wetzler MJ, Bartolozzi AR, Gillespie MJ, Rubenstein DL, Ciccotti MG, Miller LS: Revision anterior cruciate ligamentreconstruction. Oper Tech Orthop 1996, 6:181-189.

13. Greis PE, Johnson DL, Fu FH: Revision anterior cruciate ligament surgery: causes of graft failure and technical considerations of revision surgery. Clin Sports Med 1993, 12:839-852.

14. Wetzler MJ, Getelman MH, Friedman MJ, Bartolozzi AR: Revision anterior cruciate ligament surgery: etiology of failures. Oper Tech Orthop 1998, 6:64-70

15. Salmon L, Russell V, Musgrove T, Pinczewski L, Refshauge $K$ : Incidence and risk factors for graft rupture and contralateral rupture after anterior cruciate ligament reconstruction. Arthroscopy 2005, 21:948-957.

16. Otsubo H, Shino K, Nakamura N, Nakata K, Nakagawa S, Koyanagi M: Arthroscopic evaluation of $\mathrm{ACL}$ grafts reconstructed with the anatomical two-bundle technique using hamstring tendon autograft. Knee Surg Sports Traumatol Arthrosc 2007, 15:720-728.

17. Shino K, Mae T, Maeda A, Miyama T, Shinjo H, Kawakami H: Graft fixation with predetermined tension using a new device, the double spike plate. Arthroscopy 2002, 18:908-911.

18. Krosshaug T, Nakamae A, Boden BP, Engebretsen L, Smith G, Slauterbeck JR, Hewett TE, Bahr R: Mechanisms of anterior cruciate ligament injury in basketball: video analysis of 39 cases. Am J Sports Med 2007, 35:359-367.

19. Pinczewski LA, Deehan DJ, Salmon $\amalg$, Russell VJ, Clingeleffer A: A five-year comparison of patellar tendon versus four-strand hamstring tendon autograft for arthroscopic reconstruction of the anterior cruciate ligament. Am J Sports Med 2002, 30:523-536.

20. Gobbi A, Francisco R: Factors affecting return to sports after anterior cruciate ligament reconstruction with patellar tendon and hamstring graft: a prospective clinical investigation. Knee Surg Sports Traumatol Arthrosc 2006, 14:1021-1028.

21. Corry IS, Webb JM, Clingeleffer AJ, Pinczewski LA: Arthroscopic reconstruction of the anterior cruciate ligament. A comparison of patellar tendon autograft and four-strand hamstring tendon autograft. Am J Sports Med 1999, 27:444-454.

22. Shaieb MD, Kan DM, Chang SK, Marumoto JM, Richardson AB: A prospective randomized comparison of patellar tendon versus semitendinosus and gracilis tendon autografts for anterior cruciate ligament reconstruction. Am J Sports Med 2002, 30:214-220.

23. de Jong SN, van Caspel DR, van Haeff MJ, Saris DB: Functional assessment and muscle strength before and after reconstruction of chronic anterior cruciate ligament lesions. Arthroscopy 2007, 23:21-28.

24. Yasuda K, Ohkoshi Y, Tanabe Y, Kaneda K: Quantitative evaluation of knee instability and muscle strength after anterior cruciate ligament reconstruction using patellar and quadriceps tendon. Am J Sports Med 1992, 20:471-475.
25. Kobayashi A, Higuchi H, Terauchi M, Kobayashi F, Kimura M, Takagishi K: Muscle performance after anterior cruciate ligament reconstruction. Int Orthop 2004, 28:48-51.

26. Keays SL, Bullock-Saxton J, Keays AC, Newcombe P: Muscle strength and function before and after anterior cruciate ligament reconstruction using semitendonosus and gracilis. Knee 2001, 8:229-234.

27. Keays SL, Bullock-Saxton JE, Newcombe P, Keays AC: The relationship between knee strength and functional stability before and after anterior cruciate ligament reconstruction. J Orthop Res 2003, 21:231-237.

28. Wilk KE, Reinold MM, Hooks TR: Recent advances in the rehabilitation of isolated and combined anterior cruciate ligament injuries. Orthop Clin North Am 2003, 34:107-137.

29. Palmieri-Smith RM, Thomas AC, Wojtys EM: Maximizing quadriceps strength after ACL reconstruction. Clin Sports Med 2008, 27:405-424.

doi:10.1186/1758-2555-2-7

Cite this article as: Tanaka et al:: Retear of anterior cruciate ligament grafts in female basketball players: a case series. Sports Medicine, Arthroscopy, Rehabilitation, Therapy \& Technology 2010 2:7.

\section{Submit your next manuscript to BioMed Central and take full advantage of:}

- Convenient online submission

- Thorough peer review

- No space constraints or color figure charges

- Immediate publication on acceptance

- Inclusion in PubMed, CAS, Scopus and Google Scholar

- Research which is freely available for redistribution

Submit your manuscript at www.biomedcentral.com/submit
Ciomed Central 